\title{
Does Primary Tumour Location Affect the Prognosis of Patients with Colorectal Cancer Peritoneal Metastases Treated with Cytoreductive Surgery and Hyperthermic Intraperitoneal Chemotherapy?
}

\section{Haipeng Chen}

Cancer Hospital Chinese Academy of Medical Sciences

Sicheng Zhou

Cancer Hospital Chinese Academy of Medical Sciences

Jianjun Bi

Cancer Hospital Chinese Academy of Medical Sciences

Qiang Feng

Cancer Hospital Chinese Academy of Medical Sciences

Zheng Jiang

Cancer Hospital Chinese Academy of Medical Sciences

Jianping $\mathrm{Xu}$

Cancer Hospital Chinese Academy of Medical Sciences

Wei Pei ( $\sim$ peiweifbwk@163.com )

Cancer Hospital Chinese Academy of Medical Sciences

Jianwei Liang

Cancer Hospital Chinese Academy of Medical Sciences

Zhixiang Zhou

Cancer Hospital Chinese Academy of Medical Sciences

Xishan Wang

Cancer Hospital Chinese Academy of Medical Sciences

\section{Research Article}

Keywords: cytoreductive surgery, hyperthermic intraperitoneal chemotherapy,primary tumour location,prognosis

Posted Date: June 21st, 2021

DOI: https://doi.org/10.21203/rs.3.rs-626297/v1 
License: (c) (i) This work is licensed under a Creative Commons Attribution 4.0 International License. Read Full License 


\section{Abstract}

Background The impact of primary tumour location on the prognosis of patients with peritoneal metastasis (PM) arising from colorectal cancer (CRC) after cytoreductive surgery (CRS) and hyperthermic intraperitoneal chemotherapy (HIPEC) is rarely discussed, and the evidence is still limited.

Methods Patients with PM arising from CRC treated with CRS and HIPEC at the China National Cancer Center and Huanxing Cancer Hospital between June 2017 and June 2019 were systematically reviewed. Clinical characteristics, pathological features, perioperative parameters, and prognostic data were collected and analysed.

Results A total of 70 patients were divided into two groups according to colonic or rectal origin (18 patients in the rectum group and 52 patients in the colon group). Patients with PM of colonic origin were more likely to develop grade $3-4$ postoperative complications after CRS+HIPEC (38.9\% vs $19.2 \%$, $P=0.094)$, but this difference was not statistically significant. Patients with colon cancer had a longer median overall survival (OS) than patients with rectal cancer ( 27.0 vs 15.0 months, $P=0.011$ ). On the multivariate analysis, independent prognostic factors of reduced OS were rectal origin (HR $2.03,95 \% \mathrm{Cl}$ $1.02-4.24, P=0.044)$ and incomplete cytoreduction (HR 2.33, 95\% $\mathrm{Cl} 1.05-5.28, P=0.039)$.

Conclusion CRS is an originally complex and potentially life-threatening procedure, and we suggest that the indications for CRS+HIPEC in patients with PM of rectal origin be more restrictive and cautious.

\section{Introduction}

Colorectal cancer (CRC) is one of the most common malignant tumours in the world, and its morbidity and mortality rank third and fourth, respectively ${ }^{[1]}$. Among patients with $\mathrm{CRC}, 5 \%-15 \%$ have synchronous peritoneal metastasis (PM), and the incidence of metachronous PM is as high as $20-50 \%{ }^{[2]}$. PM arising from CRC is a type of tumour in the terminal stage with a very poor prognosis. Palliative surgery and systemic chemotherapy are mostly adopted, but the therapeutic effect is poor, and the median survival time is only 5 to 7 months ${ }^{[3]}$. Currently, cytoreductive surgery (CRS) combined with hyperthermic intraperitoneal chemotherapy (HIPEC) has shown good clinical efficacy in the comprehensive treatment of various malignant peritoneal diseases, including CRC, ovarian cancer and appendiceal mucous adenocarcinoma, and it has been considered a standard therapy for prolonging the survival of patients with $\mathrm{PM}$ arising from $\mathrm{CRC}^{[4-8]}$.

At present, most literature has demonstrated that a high peritoneal cancer index ( $\mathrm{PCl})$, incomplete cytoreduction, young age and postoperative complications are poor prognostic factors after CRS + HIPEC $^{[9-12]}$. It has been well established that different primary tumour locations have different biological behaviours and prognoses ${ }^{[13]}$. However, the impact of primary tumour location on the prognosis of patients with PM arising from CRC after CRS + HIPEC is rarely discussed, and the evidence is still limited $^{[14-17]}$. It is highly desirable to optimize patient selection for those most likely to benefit from this 
complex and potentially life-threatening procedure. Therefore, the aim of this study was to explore the impact of primary tumour location according to colon or rectal origin on the prognosis of patients with PM arising from CRC treated with CRS + HIPEC in our institution.

\section{Methods}

\section{Study design and patients}

The study protocol was approved by the Ethics Committee of the Cancer Hospital, Chinese Academy of Medical Sciences (NCC2017-YZ-026, October 17, 2017). The data of all patients with synchronous or metachronous PM arising from CRC who underwent CRS with HIPEC at the National Cancer Center and Huanxing Cancer Hospital were retrospectively obtained from a prospectively maintained database between June 2017 and June 2019. Patients with appendiceal tumours, liver metastasis, poor liver and kidney functions, and a history of other malignant tumours were excluded. According to the location of the primary tumour, all enrolled patients were divided into a colon group $(n=52)$ and a rectal group $(n=$ 18).

Demographic and clinical variables, as well as perioperative and long-term survival outcomes, were collected and compared. All enrolled patients underwent a routine preoperative evaluation, which included laboratory examinations, abdominal contrast-enhanced computed tomography, pelvic magnetic resonance imaging, and fluorodeoxyglucose positron emission tomography, to assess their general condition. According to the Sugarbaker/Jacquet classification, peritoneal disease burden and the completeness of cytoreduction were assessed using the $\mathrm{PCl}$ and completeness of cytoreduction (CC) score, respectively ${ }^{[18,19]}$. All postoperative complications were graded using the Clavien-Dindo classification according to the treatment received ${ }^{[20]}$.

\section{Surgical Technique}

The surgical techniques adopted at our institution have been previously described ${ }^{[9,21]}$. Briefly, HIPEC was delivered in a closed fashion, with oxaliplatin $\left(200 \mathrm{mg} / \mathrm{m}^{2}\right)$ and raltitrexed $\left(3 \mathrm{mg} / \mathrm{m}^{2}\right)$, combined with or without lobaplatin $\left(50 \mathrm{mg} / \mathrm{m}^{2}\right)$. Then, patients were treated with a mixed solution of chemotherapy agents and $3 \mathrm{~L}$ of saline solution in the abdominal and pelvic cavity for $60 \mathrm{~min}$ at $42-43^{\circ} \mathrm{C}$. Next, two additional HIPEC procedures were performed on the second and fourth days after surgery in both groups. Furthermore, two surgical specialists with more than 20 years of experience in gastrointestinal surgery performed the operations at the two centres, and the HIPEC technique and postoperative treatment were identical.

\section{Statistical analysis}


Data between two groups were analysed with SPSS 24.0 software (IBM, Armonk, NY, USA). Categorical data are expressed as percentages and were compared using the $\chi 2$ test or Fisher's exact test as appropriate. Continuous data are expressed as the mean \pm standard deviation and were compared using Student's t-test and the Mann-Whitney $\mathrm{U}$ test for independent values with normally and nonnormally distributed values, respectively. Overall survival (OS) was defined as the time from surgery to the time of death by recurrence or metastasis or July 31,2020, whichever came first. The Kaplan-Meier method and log-rank test were utilized to evaluate associations between individual factors and OS. Variables found to be significant $(P$ value $<0.05)$ in the univariate analysis were incorporated into the multivariate analysis to identify independent predictors of OS. A $P$ value $<0.05$ was considered statistically significant.

\section{Results}

\section{Demographic and clinical variables}

A total of 70 patients with PM of CRC origin who underwent CRS + HIPEC were included in the present study. Of these patients, 18 (25.7\%) had rectal cancer and 52 (74.3\%) had colon cancer. The mean age of all patients was 54.5 years, and the majority $(55.7 \%)$ of patients in the study were male. Patients were well balanced across the two groups in terms of age, sex, body mass index (BMI), preoperative comorbidity, preoperative chemotherapy, presentation of PM, preoperative CEA level, preoperative CA19-9 level, histology, and adjuvant chemotherapy $(P>0.05)$ (Table 1). 
Table 1

Patient characteristics

\begin{tabular}{|c|c|c|c|c|}
\hline Characteristics & $\begin{array}{l}\text { Total } \\
(n=70)\end{array}$ & $\begin{array}{l}\text { Rectum } \\
(n=18)\end{array}$ & $\begin{array}{l}\text { Colon } \\
(n=52)\end{array}$ & $P$ \\
\hline Age at operation (years, mean $\pm S D$ ) & $54.5 \pm 11.6$ & $52.7 \pm 12.2$ & $55.2 \pm 11.6$ & 0.451 \\
\hline Gender (\%) & & & & 0.571 \\
\hline Male & $39(55.7)$ & $9(50.0)$ & $30(57.7)$ & \\
\hline Female & $31(44.3)$ & $9(50.0)$ & $22(42.3)$ & \\
\hline Body Mass index $\left(\mathrm{kg} / \mathrm{m}^{2}\right.$, mean $\left.\pm \mathrm{SD}\right)$ & $22.7 \pm 3.6$ & $23.8 \pm 3.9$ & $22.8 \pm 3.5$ & 0.665 \\
\hline Comorbidity & & & & 0.936 \\
\hline Presence & $18(25.7)$ & $4(22.2)$ & $14(26.9)$ & \\
\hline Absence & $52(74.3)$ & $14(77.8)$ & $38(73.1)$ & \\
\hline Preoperative chemotherapy (\%) & & & & 0.477 \\
\hline Presence & $30(42.9)$ & $9(50.0)$ & $21(40.4)$ & \\
\hline Absence & $40(57.1)$ & $9(50.0)$ & $31(59.6)$ & \\
\hline Presentation of PM (\%) & & & & 0.118 \\
\hline Synchronous & $42(60.0)$ & $8(44.4)$ & $34(65.4)$ & \\
\hline Metachronous & $28(40.0)$ & $10(55.6)$ & $18(34.6)$ & \\
\hline Preoperative CEA level (ng, mean $\pm S D$ ) & $31.9 \pm 61.5$ & $16.6 \pm 27.2$ & $37.2 \pm 69.8$ & 0.290 \\
\hline Preoperative CA19-9 level $(\mathrm{ng}$, mean \pm SD) & $75.4 \pm 93.3$ & $69.2 \pm 112.4$ & $77.5 \pm 88.4$ & 0.780 \\
\hline Histology (\%) & & & & 0.275 \\
\hline Adenocarcinoma & $43(61.4)$ & $13(72.2)$ & $30(57.7)$ & \\
\hline Mucinous & $27(38.6)$ & $5(27.8)$ & $22(42.3)$ & \\
\hline Adjuvant chemotherapy & & & & 0.924 \\
\hline Presence & $55(78.6)$ & $14(77.8)$ & $41(78.8)$ & \\
\hline Absence & $15(21.4)$ & $4(22.2)$ & $11(21.2)$ & \\
\hline
\end{tabular}

\section{Operative And Perioperative Data}


Operative details and postoperative courses are listed in Table 2. The mean PCl of all enrolled patients was 11.1, and complete cytoreduction (CC $0-1$ ) was achieved in most patients (68.6\%). Patients in both groups experienced comparable mean operative times ( 255.5 vs $257.4 \mathrm{~min}, P=0.922$ ) and estimated blood loss ( 98.9 vs $130.2 \mathrm{ml}, P=0.301$ ). Compared with patients in the colon group, patients in the rectum group were more likely to develop postoperative grade $3-4$ complications $(38.9 \%$ vs $19.2 \%, P=$ $0.094)$, but this difference was not statistically significant. lleus (7.1\%) and pelvic cavity abscesses (7.1\%) were the most common postoperative complications, followed by anastomosis leakage (5.7\%), wound infection (2.9\%), pneumonia (5.4\%), pleural effusion (1.4\%), cardiac arrhythmia (1.4\%), urinary retention (1.4\%), and rectovaginal leakage (1.4\%). Two patients $(2.9 \%)$ required revision surgery due to extensive pelvic cavity abscesses, and postoperative bleeding. 
Table 2

Operative and perioperative data

\begin{tabular}{|c|c|c|c|c|}
\hline Characteristic & $\begin{array}{l}\text { Total } \\
(n=70)\end{array}$ & $\begin{array}{l}\text { Rectum } \\
(n=18)\end{array}$ & $\begin{array}{l}\text { Colon } \\
(n=52)\end{array}$ & $P$ \\
\hline Operation method & & & & 0.538 \\
\hline Laparoscopic surgery & $14(20.0)$ & $5(27.8)$ & $9(17.3)$ & \\
\hline Open surgery & $56(80.0)$ & $13(72.2)$ & $43(82.7)$ & \\
\hline HIPEC regimen & & & & 0.900 \\
\hline Lobaplatin + Oxaliplatin + Raltitrexed & $32(45.7)$ & $8(44.4)$ & $24(46.2)$ & \\
\hline Oxaliplatin + Raltitrexed & $38(54.3)$ & $10(55.6)$ & $28(53.8)$ & \\
\hline $\mathrm{PCl}$ score $($ mean $\pm \mathrm{SD})$ & $11.1 \pm 6.0$ & $11.7 \pm 6.9$ & $10.8 \pm 5.8$ & 0.600 \\
\hline Presence of ascites & & & & 0.693 \\
\hline Presence & $30(42.9)$ & 7 (38.9) & $23(44.2)$ & \\
\hline Absence & $40(57.1)$ & $11(61.1)$ & $29(55.8)$ & \\
\hline CC score & & & & 0.168 \\
\hline $\mathrm{CC} 0-1$ & $48(68.6)$ & $10(55.5)$ & $38(73.1)$ & \\
\hline CC $2-3$ & $22(31.4)$ & $8(44.5)$ & $14(26.9)$ & \\
\hline Operative time, $\min ($ mean $\pm S D)$ & $256.9 \pm 66.0$ & $\begin{array}{l}255.5 \pm \\
83.5\end{array}$ & $257.4 \pm 60.4$ & 0.922 \\
\hline Estimated blood loss, $\mathrm{ml}($ mean $\pm \mathrm{SD})$ & $\begin{array}{l}122.1 \pm \\
109.2\end{array}$ & $98.9 \pm 82.9$ & $\begin{array}{l}130.2 \pm \\
117.5\end{array}$ & 0.301 \\
\hline Postoperative complications (grades $\mathbb{\nabla}, \mathrm{IV}$ ) & $17(24.3)$ & $7(38.9)$ & $10(19.2)$ & 0.094 \\
\hline Postoperative bleeding & $2(2.9)$ & $1(5.6)$ & $1(1.9)$ & \\
\hline Anastomosis leakage & $4(5.7)$ & $2(11.1)$ & $2(3.8)$ & \\
\hline Pelvic cavity abscess & $5(7.1)$ & $2(11.1)$ & $3(5.8)$ & \\
\hline lleus & $5(7.1)$ & $2(11.1)$ & $3(5.8)$ & \\
\hline Pneumonia & $1(1.4)$ & $1(5.6)$ & $0(0)$ & \\
\hline Pleural effusion & $1(1.4)$ & $1(5.6)$ & $0(0)$ & \\
\hline Cardiac arrhythmia & $1(1.4)$ & $0(0)$ & $1(1.9)$ & \\
\hline
\end{tabular}

Note: $H I P E C$ standard hyperthermic intraperitoneal chemotherapy; $P C /$ standard peritoneal cancer index $\square C C$ standard complete cytoreduction 


\begin{tabular}{|lllll|}
\hline Characteristic & $\begin{array}{l}\text { Total } \\
(\mathbf{n}=\mathbf{7 0})\end{array}$ & $\begin{array}{l}\text { Rectum } \\
(\mathbf{n}=\mathbf{1 8})\end{array}$ & $\begin{array}{l}\text { Colon } \\
(\mathbf{n}=\mathbf{5 2})\end{array}$ & \\
\hline Wound infection & $2(2.9)$ & $1(5.6)$ & $1(1.9)$ & \\
\hline Urinary retention & $1(1.4)$ & $0(0)$ & $1(1.9)$ & \\
\hline Rectovaginal leakage & $1(1.4)$ & $0(0)$ & $1(1.9)$ & \\
\hline $\begin{array}{l}\text { Postoperative hospital stay, day (mean } \pm \\
\text { SD) }\end{array}$ & $14.6 \pm 5.3$ & $15.4 \pm 4.7$ & $14.3 \pm 5.6$ & \\
\hline $\begin{array}{l}\text { Re-operation } \\
\text { Mortality }\end{array}$ & $2(2.9)$ & $1(5.6)$ & $1(5.6)$ & - \\
\hline $\begin{array}{l}\text { Note: } H I P E C \text { standard hyperthermic intraperitoneal chemotherapy; } P C / \text { standard peritoneal cancer } \\
\text { index } \square C C \text { standard complete cytoreduction }\end{array}$ & $0(0)$ & 000 & \\
\hline
\end{tabular}

\section{Overall Survival}

The median estimated follow-up period from CRS/HIPEC for the study population was 20 months. The median survival period for all patients was 25 months, and the estimated 1-, 2- and 3-year OS rates for the entire cohort were $72.6 \%, 51.4 \%$, and $40.1 \%$, respectively(Fig. 1). The median OS for those with colon cancer was 27 months compared with 15 months for those with rectal cancer $(P=0.011)$ (Fig. 2$)$. The median OS from CRS + HIPEC in patients undergoing incomplete cytoreduction (CC 2-3) was 12 months, while the median OS was not reached in patients undergoing complete cytoreduction (CC $0-1)$ (Fig. 3). On the Cox univariate regression analysis, factors found to be associated with reduced OS were increasing $\mathrm{PCl}$ (HR 1.09, 95\% Cl 1.03-1.14, $P=0.002$ ), rectal origin (HR 2.54, 95\% Cl 1.24-5.18, $P=0.011$ ), and incomplete cytoreduction (HR 3.49,95\% $\mathrm{Cl} 1.77-6.87, P<0.001)$. On the multivariate analysis, independent prognostic factors of reduced OS were rectal origin (HR 2.03,95\% $\mathrm{Cl} 1.02-4.24, P=0.044$ ) and incomplete cytoreduction (HR 2.33, 95\% Cl 1.05-5.28, $P=0.039$ )(Table 3 ). 
Table 3

Univariate analysis and Multivariate analysis

\begin{tabular}{|c|c|c|c|c|}
\hline \multirow[t]{3}{*}{ Variables } & \multicolumn{4}{|c|}{ Overall survival } \\
\hline & \multicolumn{2}{|c|}{ Univariate analysis } & \multicolumn{2}{|c|}{ Multivariate analysis } \\
\hline & $\mathrm{HR}(95 \% \mathrm{Cl})$ & $\mathbf{P}$ & $\mathrm{HR}(95 \% \mathrm{Cl})$ & $\mathbf{P}$ \\
\hline Gender: male/female & $\begin{array}{l}1.32(0.66- \\
2.64)\end{array}$ & 0.434 & & \\
\hline Age at operation & $\begin{array}{l}1.02(0.98- \\
1.05)\end{array}$ & 0.283 & & \\
\hline Preoperative chemotherapy (no/yes) & $\begin{array}{l}1.22(0.53- \\
2.80)\end{array}$ & 0.635 & & \\
\hline Synchronous/metachronous & $\begin{array}{l}1.46(0.73- \\
2.93)\end{array}$ & 0.288 & & \\
\hline Site of original (rectum/colon) & $\begin{array}{l}2.54(1.24- \\
5.18)\end{array}$ & 0.011 & $\begin{array}{l}2.03(1.02- \\
4.24)\end{array}$ & 0.044 \\
\hline Histology (mucinous/adenocarcinoma) & $\begin{array}{l}1.53(0.78- \\
3.00)\end{array}$ & 0.215 & & \\
\hline Preoperative CEA level & $\begin{array}{l}1.00(0.99- \\
1.00)\end{array}$ & 0.279 & & \\
\hline Preoperative CA19-9 level & $\begin{array}{l}1.00(0.99- \\
1.00)\end{array}$ & 0.247 & & \\
\hline HIPEC regimen (lobaplatin/non-lobaplatin) & $\begin{array}{l}0.63(0.31- \\
1.28)\end{array}$ & 0.199 & & \\
\hline Presence of ascites (yes/no) & $\begin{array}{l}1.33(0.68- \\
2.60)\end{array}$ & 0.410 & & \\
\hline PCI score & $\begin{array}{l}1.09(1.03- \\
1.14)\end{array}$ & 0.002 & $\begin{array}{l}1.05(0.98- \\
1.11)\end{array}$ & 0.181 \\
\hline CC score $(2-3 / 0-1)$ & $\begin{array}{l}3.49(1.77- \\
6.87)\end{array}$ & $<001$ & $\begin{array}{l}2.33(1.05- \\
5.28)\end{array}$ & 0.039 \\
\hline $\begin{array}{l}\text { Grade 3-4 Postoperative complication } \\
\text { (no/yes) }\end{array}$ & $\begin{array}{l}1.63(0.77- \\
3.42)\end{array}$ & 0.201 & & \\
\hline Leukopenia (no/yes) & $\begin{array}{l}0.67(0.28- \\
1.63)\end{array}$ & 0.382 & & \\
\hline Neutropenia (no/yes) & $\begin{array}{l}0.80(0.33- \\
1.94)\end{array}$ & 0.626 & & \\
\hline Thrombocytopenia (no/yes) & $\begin{array}{l}0.49(0.15- \\
1.63)\end{array}$ & 0.245 & & \\
\hline
\end{tabular}




\section{Discussion}

Primary tumour location is recognized as one of the important prognostic factors for metastatic CRC, and it is also a selection factor for the use of different targeted medicines ${ }^{[13]}$. However, the impact of primary tumour location on the prognosis of CRC patients undergoing CRS + HIPEC due to PM is rarely discussed, and the evidence is still limited ${ }^{[14-17]}$. Therefore, we conducted a novel study to demonstrate the differences in different primary tumour locations among patients with PM arising from CRC and focused on their significant impacts on perioperative outcomes and long-term prognoses.

In the present study, 70 enrolled patients were divided into two groups according to the origin of the primary tumour: the colon group (52 patients) and the rectal group (18 patients). Our results revealed that patients with colon cancer-derived PM had a longer median survival after CRS + HIPEC (27.0 vs 15.0 months, $P=0.011$ ), and primary tumour location remained an independent predictor of OS (HR 2.03, 95\% $\mathrm{Cl} 1.02-4.24, P=0.044)$. In 2018 , Tonello et al ${ }^{[15]}$. published a paper in which they analysed survival in patients with colorectal PM treated with CRS + HIPEC and reported that PM of rectal origin was associated with worse long-term survival outcomes than PM of colonic origin (median OS: 47.8 vs 22.0 months, $P=0.008)$. Similarly, Da Silva et al ${ }^{[14]}$. also demonstrated that the median survival in patients with PM of colonic origin was significantly better than that in patients with PM of rectal origin (35.0 vs 17.0 months). The above research results are basically consistent with ours.

Several theories have been proposed to explain this difference in terms of the prognosis of PM of rectal origin. Anatomically, a rectal tumour is located in the narrow pelvic cavity, which makes resection of the primary tumour and pelvic peritoneal metastasis difficult; therefore, it is difficult to achieve complete cytoreduction, and the possibility of a residual tumour is increased ${ }^{[22]}$. Low-middle rectal cancer (under the peritoneum) increases the risk of perforating the rectal wall, which is thicker than the colon wall and is therefore biologically more aggressive ${ }^{[14]}$.

Close attention has been given to the morbidity and mortality associated with the CRS + HIPEC procedure. Our institution confirmed that the grade 3-4 morbidity rate and mortality rate after CRS + HIPEC were $24.3 \%$ and $0 \%$, respectively, which is basically consistent with the results reported by international centres $^{[7,23-26]}$. Notably, we also found that patients with PM of rectal origin were more likely to develop grade 3-4 postoperative complications after CRS + HIPEC than patients with PM of colonic origin (38.9\% vs $19.2 \%, P=0.094$ ), but this difference was not statistically significant. CRS is an originally complex and potentially life-threatening procedure. Due to the special anatomical location of rectal tumours, the narrow operating space further increases the difficulty of CRS.

The limitations of this study are those inherent to a single institution with a limited sample size, which may have caused some of the differences observed between the rectal group and the colon group. Second, this study was also limited by its retrospective nature, which makes it difficult to control for bias and confounders. Therefore, we recommend caution when making any definitive conclusions, and multicentre prospective randomized controlled studies are required to further verify our results. 


\section{Conclusion}

These findings demonstrated that the $\mathrm{CC}$ score and primary tumour location were independent prognostic factors after CRS + HIPEC in patients with PM of CRC origin. In addition, patients with PM of colonic origin were more likely to develop postoperative complications after CRS + HIPEC. We suggest that the indications for CRS + HIPEC in patients with PM of rectal origin should be more restrictive and cautious.

\section{List Of Abbreviations}

peritoneal metastasis (PM)

colorectal cancer (CRC)

cytoreductive surgery (CRS)

hyperthermic intraperitoneal chemotherapy (HIPEC)

peritoneal cancer index $(\mathrm{PCl})$

completeness of cytoreduction

Overall survival (OS)(CC)

body mass index (BMI)

\section{Declarations}

\section{Ethics approval and consent to participate}

The ethics committee of the National Cancer Center/Cancer Hospital, Chinese Academy of Medical Sciences and Peking Union Medical College approved this study. Prior written informed consent was obtained from all study participants.

\section{Consent for publication}

Not Applicable.

\section{Availability of data and material}

The datasets generated and/or analysed during the current study are not publicly available due to the data is confidential patient data but are available from the corresponding author on reasonable request.

\section{Competing interests}

The authors declare that they have no competing interests. 


\section{Funding}

This work was supported by Capital's Funds for Health Improvement and Research (2016-2-4022). The funding source didn't involve the preparation of the article.

\section{Authors' contributions}

Contributions: (I) conception and design: Jianping Xu and Wei Pei; (II) administrative support: Jianwei Liang ,Xishan Wang and Zhixiang Zhou; (III) provision of study materials or patients: Jianjun Bi囚Qiang Feng and Zheng Jiang; (IV) collection and assembly of data: Sicheng Zhou and Haipeng Chen; (V) data analysis and interpretation: Sicheng Zhou and HaiPeng Chen. All authors read and approved the final manuscript.

\section{Acknowledgements}

Not applicable.

\section{References}

1. Chen WQ, Zheng RS, Baade PD, et al. Cancer statistics in China, 2015. CA Cancer J Clin. 2016;66(2):115-32.

2. van Gestel YR, de Hingh IH, van Herk-Sukel MP, et al. Patterns of metachronous metastases after curative treatment of colorectal cancer. Cancer Epidemiol. 2014;38(4):448-54.

3. Kerscher AG, Chua TC, Gasser M, et al. Impact of peritoneal carcinomatosis in the disease history of colorectal cancer management: a longitudinal experience of 2406 patients over two decades. $\mathrm{Br} \mathrm{J}$ Cancer. 2013;108(7):1432-9.

4. Bushati M, Rovers KP, Sommariva A, et al. The current practice of cytoreductive surgery and HIPEC for colorectal peritoneal metastases: results of a worldwide web-based survey of the peritoneal surface oncology group international (PSOGI). Eur J Surg Oncol. 2018;44(12):1942-8.

5. Cashin PH, Mahteme H, Spång N, et al. Cytoreductive surgery and intraperitoneal chemotherapy versus systemic chemotherapy for colorectal peritoneal metastases: a randomised trial. Eur $\mathrm{J}$ Cancer. 2016;53:155-62.

6. Van Driel WJ, Koole SN, Sikorska K, et al. Hyperthermic Intraperitoneal chemotherapy in ovarian Cancer. N Engl J Med. 2018;378(3):230-40.

7. Klaver CEL, Wisselink DD, Punt CJA, et al. Adjuvant hyperthermic intraperitoneal chemotherapy in patients with locally advanced colon cancer (COLOPEC): a multicentre, open-label, randomised trial. Lancet Gastroenterol Hepatol. 2019;4(10):761-70.

8. Quenet F, Elias D, Roca L, et al. A UNICANCER phase III trial of hyperthermic intra-peritoneal chemotherapy (HIPEC) for colorectal peritoneal carcinomatosis (PC): PRODIGE 7. J Clin Oncol. 2018;36:18. 
9. Zhou S, Feng Q, Zhang J, et al. High-grade postoperative complications affect survival outcomes of patients with colorectal Cancer peritoneal metastases treated with Cytoreductive surgery and Hyperthermic Intraperitoneal chemotherapy. BMC Cancer. 2021;21(1):41.

10. Massalou D, Benizri E, Chevallier A, et al. Peritoneal carcinomatosis of colorectal cancer: novel clinical and molecular outcomes. Am J Surg. 2017;213(2):377-7.

11. Sipok A, Sardi A, Nieroda C, et al. Comparison of Survival in Patients with Isolated Peritoneal Carcinomatosis from Colorectal Cancer Treated with Cytoreduction and Melphalan or Mitomycin-C as Hyperthermic Intraperitoneal Chemotherapy Agent. Int J Surg Oncol,2018, 2018:1920276.

12. Solaini L, D'Acapito F, Passardi A, et al. Cytoreduction plus hyperthermic intraperitoneal chemotherapy for peritoneal carcinomatosis in colorectal cancer patients: a single-center cohort study. World J Surg Oncol. 2019;17(1):58.

13. Creasy JM, Sadot E, Koerkamp BG, et al. The impact of primary tumor location on long-term survival in patients undergoing hepatic resection for metastatic colon cancer. Ann Surg Oncol. 2018;25:4318.

14. da Silva RG, Sugarbaker PH. Analysis of prognostic factors in seventy patients having a complete cytoreduction plus perioperative intraperitoneal chemotherapy for carcinomatosis from colorectal cancer. J Am Coll Surg. 2006;203(6):878-86.

15. Tonello M, Ortega-Perez $G$, Alonso-Casado 0 , et al. Peritoneal carcinomatosis arising from rectal or colonic adenocarcinoma treated with cytoreductive surgery (CRS) hyperthermic intraperitoneal chemotherapy (HIPEC): two different diseases. Clin TransI Oncol. 2018;20(10):1268-73.

16. Verwaal VJ, van Ruth S, de Bree E, et al. Randomized trial of cytoreduction and hyperthermic intraperitoneal chemotherapy versus systemic chemotherapy and palliative surgery in patients with peritoneal carcinomatosis of colorectal cancer. J Clin Oncol. 2003;21(20):3737-43.

17. Kelly KJ, Alsayadnasser M, Vaida F, et al. Does Primary Tumor Side Matter in Patients with Metastatic Colon Cancer Treated with Cytoreductive Surgery and Hyperthermic Intraperitoneal Chemotherapy? Ann Surg Oncol. 2019;26(5):1421-7.

18. Jacquet $\mathrm{P}$, Sugarbaker $\mathrm{PH}$. Clinical research methodologies in diagnosis and staging of patients with peritoneal carcinomatosis. Cancer Treat Res. 1996;82:359-74.

19. Koh JL, Yan TD, Glenn D, et al. Evaluation of preoperative computed tomography in estimating peritoneal cancer index in colorectal peritoneal carcinomatosis. Ann Surg Oncol. 2009;16(2):327-33.

20. Dindo D, Demartines N, Clavien PA. Classification of surgical complications: a new proposal with evaluation in a cohort of 6336 patients and results of a survey. Ann Surg. 2004;240(2):205-13.

21. Pei Wei Z, Sicheng Z, Jing, et al. Lobaplatin-Based Hyperthermic Intraperitoneal Chemotherapy for Patients with Peritoneal Metastasis from Appendiceal and Colorectal Cancer: Safety and Efficacy Profiles. Cancer Manag Res. 2020;12:12099-110.

22. Sugarbaker $\mathrm{PH}$. Update on the prevention of local recurrence and peritoneal metastases in patients with colorectal cancer. World J Gastroenterol. 2014;20(28):9286-91. 
23. Solaini L, D'Acapito F, Passardi A, et al. Cytoreduction plus hyperthermic intraperitoneal chemotherapy for peritoneal carcinomatosis in colorectal cancer patients: a single-center cohort study. World J Surg Oncol. 2019;17(1):58.

24. Woeste MR, Philips P, Egger ME, et al. Optimal perfusion chemotherapy: A prospective comparison of mitomycin $\mathrm{C}$ and oxaliplatin for hyperthermic intraperitoneal chemotherapy in metastatic colon cancer. J Surg Oncol, 2020, [published online ahead of print, 2020 Apr 1].

25. Beal EW, Suarez-Kelly LP, Kimbrough CW, et al. Impact of Neoadjuvant Chemotherapy on the Outcomes of Cytoreductive Surgery and Hyperthermic Intraperitoneal Chemotherapy for Colorectal Peritoneal Metastases: A Multi-Institutional Retrospective Review. J Clin Med. 2020;9(3):748.

26. Wong JSM, Tan GHC, Chia CS, et al. The importance of synchronicity in the management of colorectal peritoneal metastases with cytoreductive surgery and hyperthermic intraperitoneal chemotherapy[J]. World J Surg Oncol. 2020;18(1):10.

\section{Figures}

\section{Overall survival}

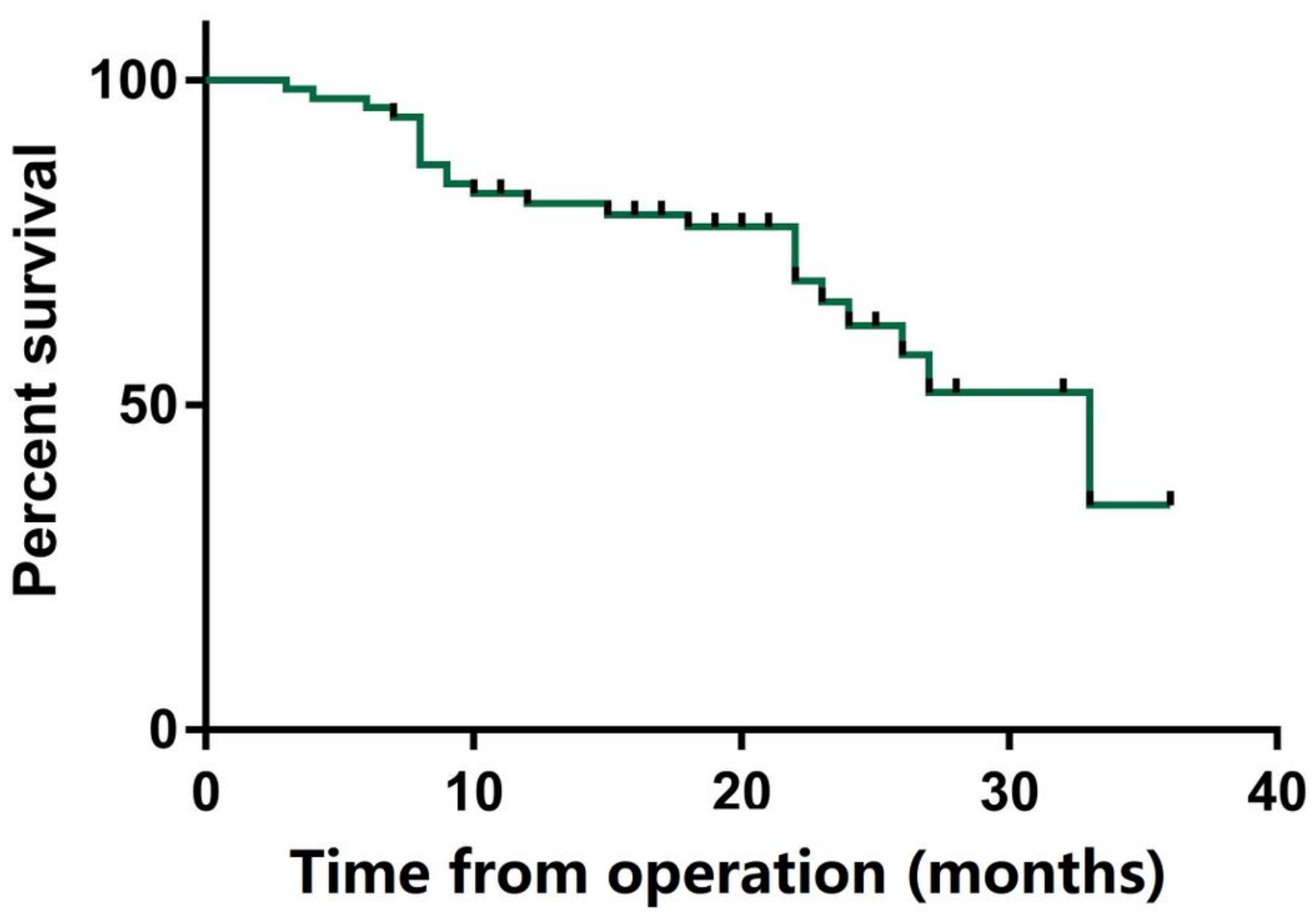


Figure 1

Overall survival of the entire cohort

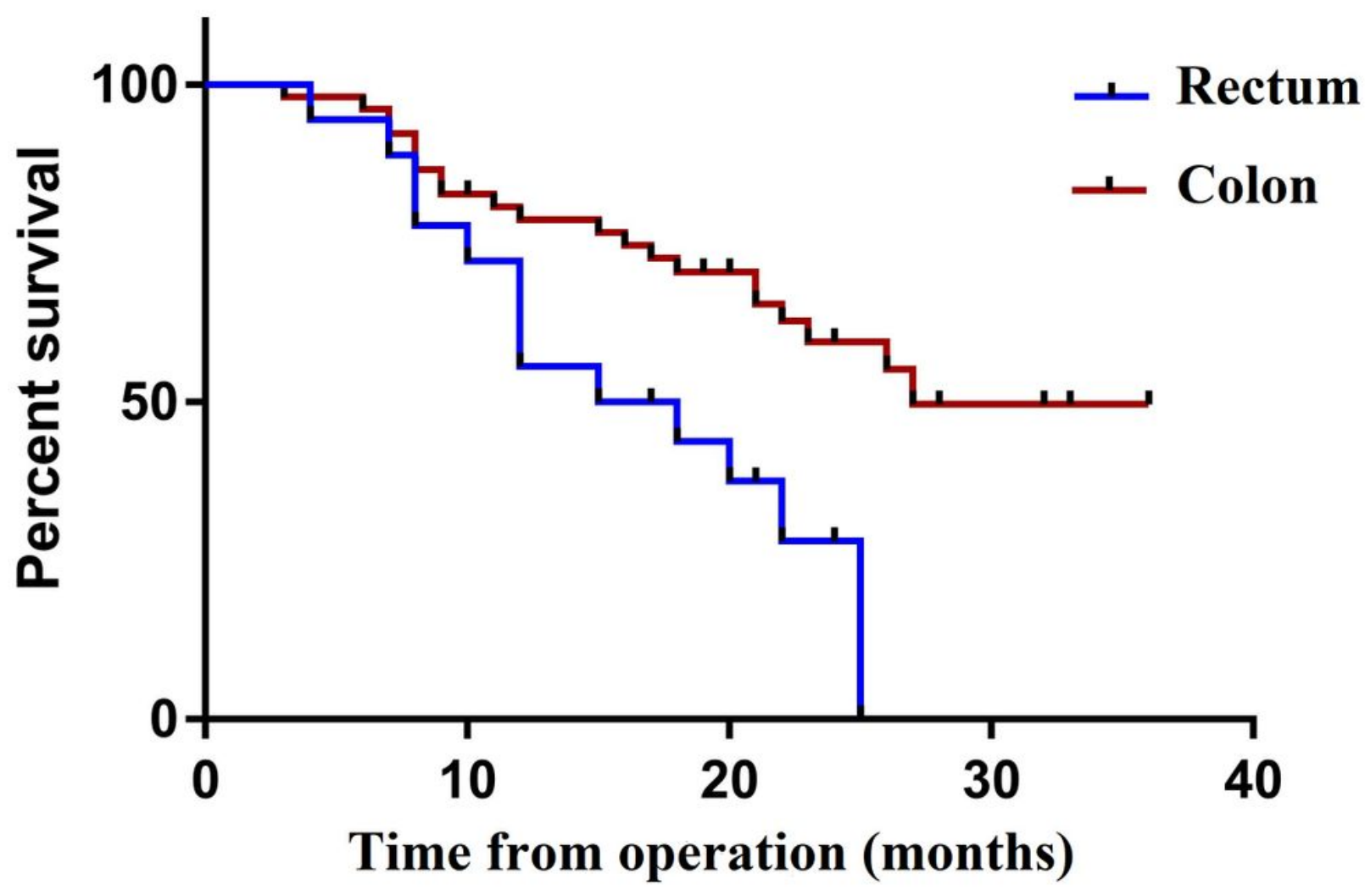

Figure 2

The median OS for those with colon cancer vs those with rectal cancer. 


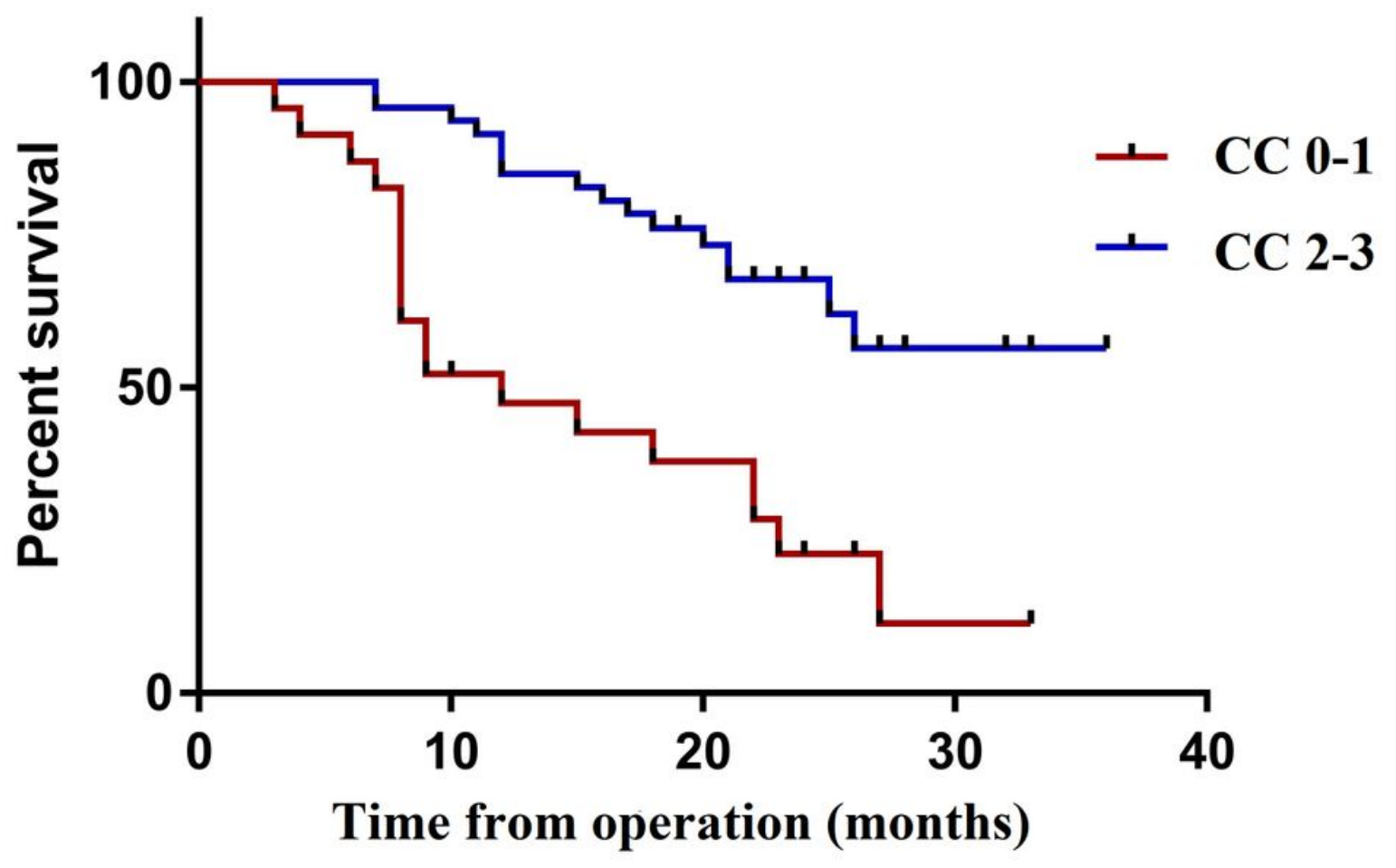

Figure 3

The median OS from CRS+HIPEC in patients undergoing incomplete cytoreduction vs complete cytoreduction. 